\title{
Trends In IT Human Resources And Its Impact On Curriculum Design
}

\author{
Vipin K Agrawal, California State University, Fullerton, USA \\ Frank Tenkorang, University of Nebraska at Kearney, USA \\ Vijay K. Agrawal, University of Nebraska at Kearney, USA \\ Allen R. Taylor, University of Nebraska at Kearney, USA
}

\begin{abstract}
In light of rapid changes in technology and business, institutions of higher education face the difficult task of adapting their curriculum to be general enough to cover all the core concepts of the discipline while being specific enough to prepare students with the knowledge and skills needed by businesses. The Bureau of Labor Statistics (BLS) forecasts that the demand for IT professionals in the United States will continue to increase but the demand will not be evenly distributed across all areas. The BLS breaks future demand into job categories but it does not explore the meta-trends that will drive future job growth and is thus of limited value for curriculum development purposes. This paper reviews existing literature and develops a conceptual framework of the meta-trends driving job growth. This framework is intended to be used as a guide by Information Technology curriculum committees to aid in establishing a curriculum that meets the needs of key stakeholders while avoiding the trap of chasing the latest fads.
\end{abstract}

Keywords: IT Demand, Curriculum Development, Systems Development, End User Computing

\section{INTRODUCTION}

\begin{abstract}
nformation Technology (IT) has become essential for most businesses. While there is some disagreement regarding whether IT should be considered a source of competitive advantage (Tapscott, 2001; Metcalfe, 2004; and others); just a tool that should be used as part of a competitive strategy (Carr, 2003; Porter, 2001; and others); or as some combination of the above (Grove, quoted in Hof, 2003) there is a general consensus that competent IT performance is critically important for a firm's survival. Even those who believe that IT is mature and no longer offers a source of competitive advantage recognize that it still has to be done well to stay competitive. For example, as Carr (2003) puts it, "Today, an IT disruption can paralyze a company's ability to make its products, deliver its services, and connect with its customers, not to mention foul its reputation."
\end{abstract}

To have competent IT performance, firms need an adequate supply of IT professionals. The challenge to universities is how not to be concerned with only rigorously teaching students the underlying theory of a field but also how to engage in continuous life-long learning. Both goals can be accomplished within a curriculum that provides students with relevant knowledge and skills that are in demand by employers. One of the reasons it is difficult to develop such a curriculum is that the technology field is in a period of tremendous change. According to futurist George Gilder (2002) the amount of technical knowledge is doubling every two years and it is expected that the pace of growth will continue to increase. Because of this rate of rapid change, university departments that offer degrees in the information technology fields will have difficult choices to make regarding how their curriculum should be structured but business schools will have to be willing to adapt quickly to the needs of their key stakeholders in order to remain viable (Fleming, 2008). Some scholars question whether it is even possible for business schools to adequately prepare their graduates for the workforce given the current structure of the schools (Mintzberg, 2004; McKenna, Cotton, and Van Auken, 1995; Bennis and O'Toole, 2005; McNamara, 2006). As a result an increasing number of businesses are choosing to train their employees in-house through corporate universities (Gerdes, 2005). Corporate University Xchange estimates that the number of corporate universities totals 
2000 which is up from only 400 about 15 years ago and they predict that the number will grow to 3,700 by 2010 (AACSB, 2002).

In this paper we will be looking at trends in IT that are likely to impact the number of IT jobs, filled or vacant. One advantage of looking at industry trends as opposed to current jobs is that long term trends are more likely to be detected since the short term vagrancies of the job market are filtered out. Another advantage of looking at industry trends is that this framework is generic enough so each institution can do an environmental scan of their area to develop a curriculum that is customized to better serve the businesses that most recruit their campus by providing graduates who are exceptionally well qualified for the needs of those businesses. At the same time, certain core concepts are so central to the IT discipline that those concepts will be part of the curriculum for all schools.

The purpose of this paper is to examine the various, sometimes contradictory, factors influencing the demand for IT professionals and to build a simple framework that can be used to predict demand with its implications on curriculum design. The ability to predict the demand for IT professionals with a reasonable degree of accuracy is important in order for institutions of higher education and businesses to correctly identify where their scarce resources should be allocated to develop a curriculum for the $21^{\text {st }}$ century workforce. Gerdes (2005) reported that for mid-tier MBA programs, focusing on niche areas has led to growth in their programs. This conceptual framework is designed to aid IS/IT department curriculum committees to use as a template when redesigning their curriculum to offer courses that will best prepare their graduates to be successful in the highly competitive job market of the present and the future. IS departments need to develop a curriculum that is general enough to prepare graduates for a rapidly changing job market while at the same time also equipping them with the knowledge they need to add as much value to a hiring firm as quickly as possible. In the curriculum review, the curriculum committee can indentify niches that are available for their particular institution by considering the framework presented in this paper. For example, if an environmental scan reveals that many businesses who are key stakeholders of the educational institution are involved in the use of business intelligence (BI) then the curriculum can be developed so that more graduates will have knowledge and skills that are valued for that application of IT. A different institution might find that they are located in an area where there key stakeholders rarely use BI but there is a huge demand for graduates with programming and system analysis and design knowledge, in which case the curriculum could be adapted to produce graduates who excel in that area.

\section{BUREAU OF LABOR STATISTICS PROJECTED GROWTH RATE}

According to Bureau of Labor Statistics (BLS) data the IT professionals' job market is one of the fastestgrowing sectors in the U.S. economy (Dohm and Shniper, 2007). Since 2000 the BLS has been making 10 year employment rolling forecasts of IT labor demand (Dohm and Shniper, 2007; Hecker, 2006; Hecker, 2004; Hecker, 2001). These forecasts are published biennially and each time future growth rates are revised. Figure 1 shows a plot of these projections. Two things are obvious from this figure. First, each projection has a positive growth rate, and second, the curves get flatter with each revision. The implication of this is that the demand for IT professionals will continue to increase but at a decreasing rate. The $2000-10$ projection has an annual growth rate of $1.05 \%$ while the 2006-16 projection has $1.02 \%$.

This declining rate of job growth projection raises an interesting question. How well have these projections historically compared with actual IT jobs? Or perhaps more to the point, are IT jobs actually increasing? Figure 2 compares actual IT professional jobs to BLS projections. In 2002, BLS was very optimistic about the IT labor market which is reflected in the more than $10 \%$ projection over actual number of jobs. In 2004, the difference reduced drastically to $2.1 \%$, and in 2006 BLS was pessimistic about the market, with the projected number of jobs being $4.4 \%$ less than the predicted jobs.

From examining Figure 2 it would appear that the increase in demand for IT professionals is actually present. The BLS predictions were perhaps overly optimistic in the 2002 forecast but subsequent forecasts have come closer to reflecting reality. This data suggests that the demand for IT professionals is growing as a whole. But

for reasons of planning curriculum and for professionals upgrading their skills sets it would be much more useful to know if there are particular job categories that are net winners and losers in the job creation process. 
Figure 1 - BLS 10-year labor projections

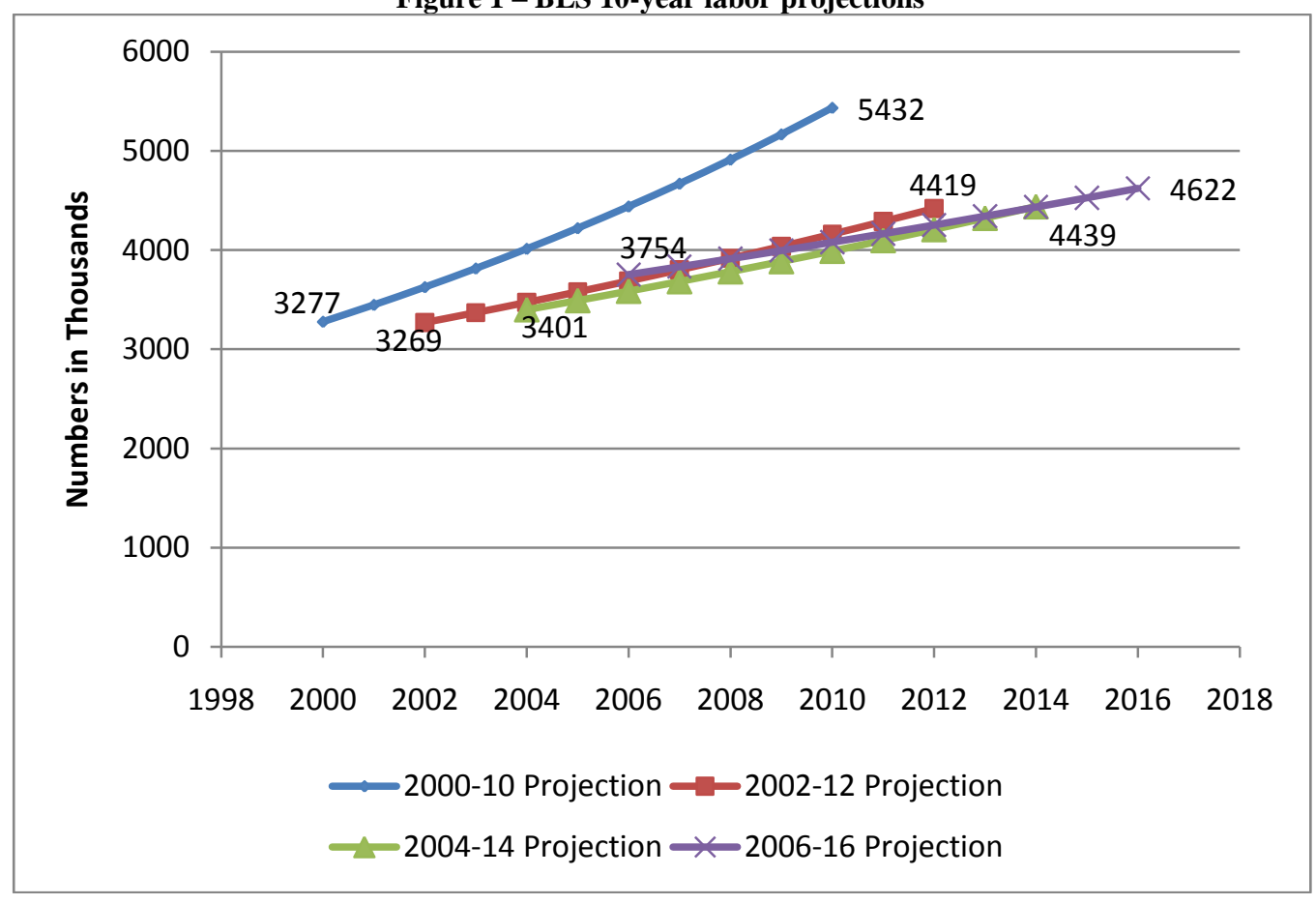

Figure 2 - Actual jobs compared to projected

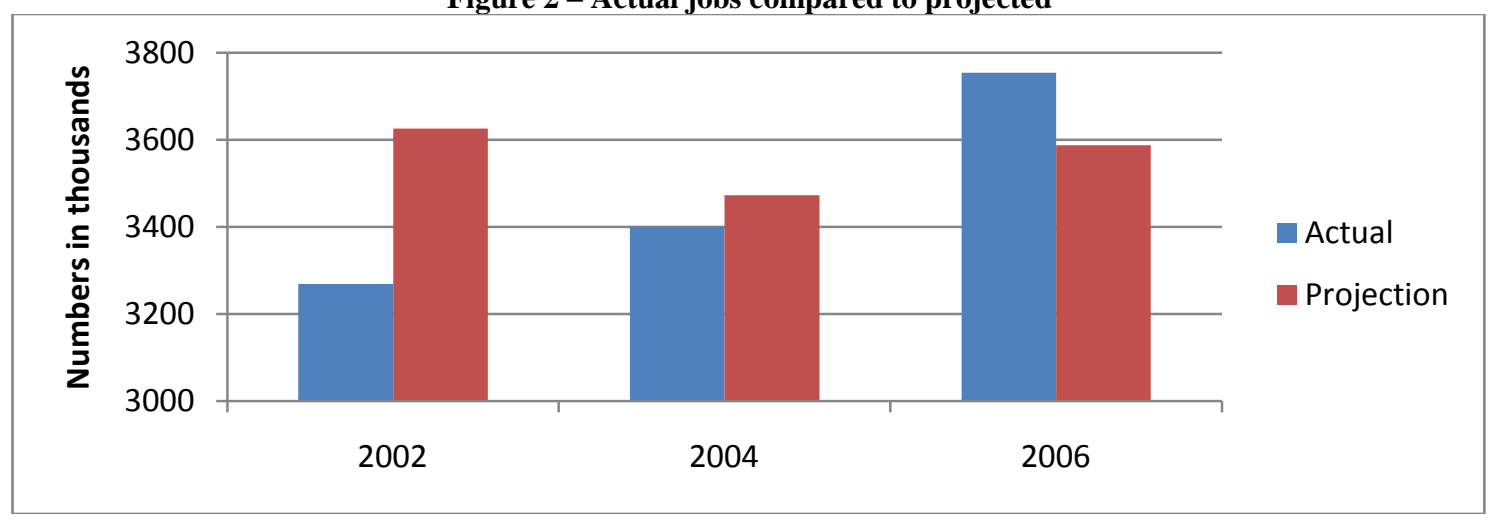

From 2000 until 2006 there was a positive overall growth rate for the development and adoption of IT applications but the growth was not across all categories. According to the BLS four out of the eleven IT professional job categories experienced declines between 2000 and 2006 as shown in Figure 3. The categories with a net decline are computer and information systems managers; computer and information scientist/research; computer specialist and all other; and computer programmers. The fastest growing IT jobs include computer hardware engineer (385\%) and network systems and data communications analyst (120\%). Computer software engineers accounts for the highest proportion of all IT professional jobs (over $21 \%$ ).

One complicating factor that makes the BLS data of very limited value for curriculum development is the fact that not only are there likely to be different job growth rates across different industry segments but also different areas will see demand for different knowledge sets. As an example, it makes sense that because the demand for computer programmers has declined and is likely to continue to decline in the United States some colleges will want to deemphasize programming in the curriculum. But that does not mean that all institutions of higher learning should 
deemphasize programming. In areas where there is a thriving vibrant business environment that needs computer programmers there would be an opportunity for colleges serving that communities needs to identify that as a strength and to serve that niche by emphasizing that area of study in their curriculum. Therefore, the needed framework is one that can serve as a lens through which trends in the community can be viewed so that areas of emphasis can be identified. Toward that end, we have identified the key factors that follow.

Figure 3 - IT jobs by category

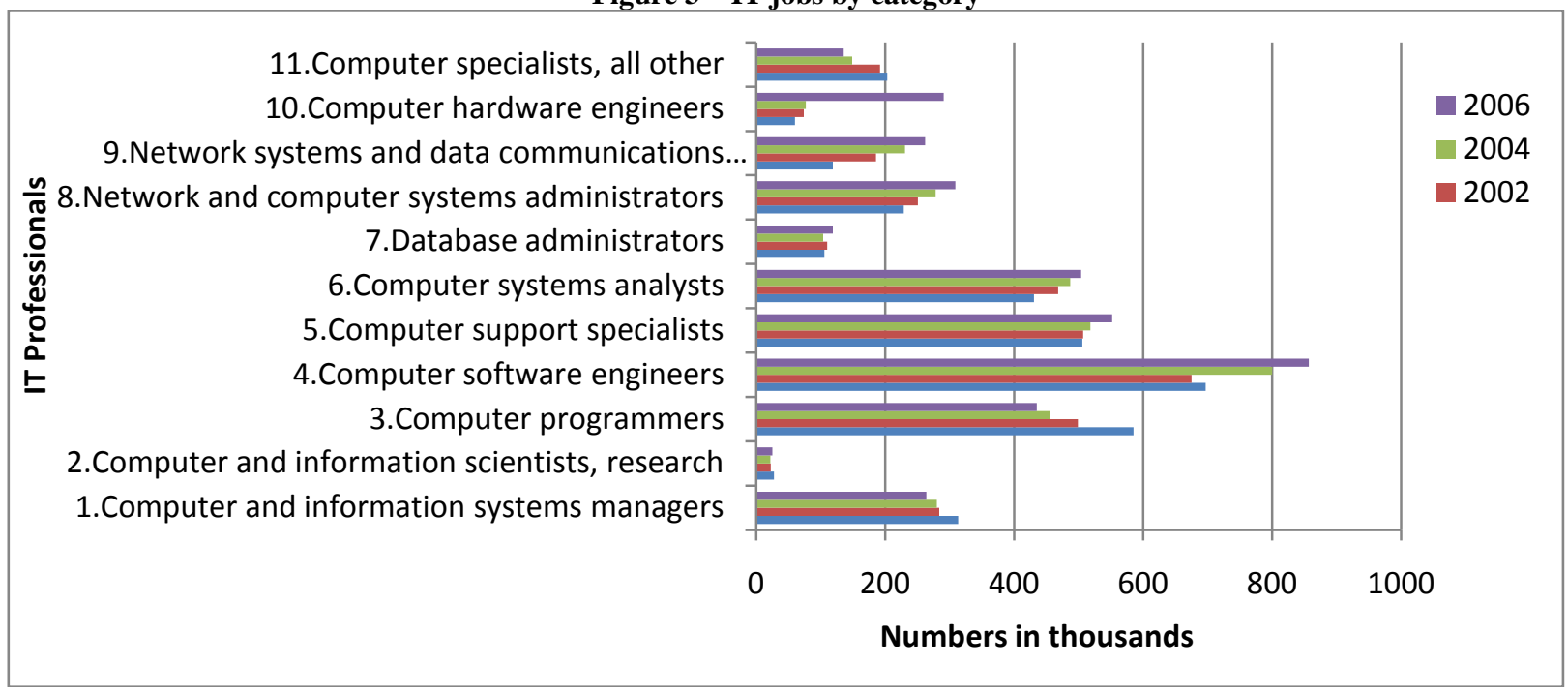

\section{DEMAND FOR IT APPLICATIONS}

The average IT investment in U.S. organizations is $4 \%$ of their sales revenue and contributes up to $50 \%$ in total capital costs (Broadbent and Weill, 1997; Mahmood and Mann, 1993). While IT is essential to most businesses survival, IT departments have not been spared from the economic realities currently impacting the global economy. According to Forrester Research Incorporated (2009), the US business and government purchases of IT goods and services are expected to decrease by $3.1 \%$ in 2009. Most of that decrease will come at the expense of hardware purchases but other areas will likely see a decrease in spending as well. Gartner (2009) predicts that IT spending will be down $3.8 \%$ overall but much of that comes at the expense of computing hardware $(-14.9 \%)$ and telecom (-2.9\%).

H1: Demand for new applications will be positively correlated with the demand for proprietary software.

H2: Demand for new applications will be positively correlated with demand for COTS software.

As shown in the framework (Figure 4), there are two possible ways a company can acquire new software. They can develop proprietary software for their sole use or they can use software that is made by another company. For the purpose of discussion we will refer to software made by other companies as Commercial Off-The-Shelf (COTS) applications.

H3: Demand for proprietary and COTS applications are negatively correlated.

\section{COMMERCIAL OFF-THE-SHELF SOFTWARE}

There are three trends that are working together to cause a shift of companies from making their own proprietary software to using COTS. These trends are shrinkage in systems life cycle, high cost and risk-prone tendency of the needed software, and desired characteristics of the software solution. Each of these serves to make the development of proprietary software more risky and less rewarding. 
The systems life cycle is shrinking as software development advances. With blurring national boundaries, the numbers of competing organizations and knowledge workers have been increasing. Additionally, the environment is turbulent, changing rapidly, and in an unpredictable manner (Applegate, 2007, Scott-Morton, 1991; Turban et al., 2001). The characteristics of this environment identified by El Sawy et al. (1999) include timecompression, short product life cycles, strategic discontinuity, increase in knowledge intensity, and a customerfocused approach. The environmental trends will make organizational processes and resulting software applications vulnerable to frequent changes. The faster obsolescence of packages will result in increase in cost of the IT applications to the organizations manifold. Li and Ye (1999) also contend that it is an era of time-based competition. The same strategy will not work for a prolonged period of time. The changes in strategy will lead to alteration in the processes and the resulting software. Matheson and Tarjan (1998) and Nidumolu and Knotts (1998) found that software firms have very short development time cycles since technology changes very rapidly. Brancheau et al. (1996) asserted that the effectiveness of software development has been a key management information systems issue since the 1980s. Agrawal (2005d) asserted that the higher rate of product obsolescence will lead to increased adoption of Enterprise Resource Planning (ERP) packages and decrease in usage of off-the-shelf applications (other than ERP packages). Under such circumstances organizations are expected to invest a minimum amount of time and money on the software, which is possible if they use off-the-shelf solutions for smaller applications and ERP packages for enterprise wide applications.

The development of software is exhibiting a high cost and risk-prone tendency. A report by Standish Group International on the success of software projects reveals that in the United States $31.1 \%$ of projects are not completed; while $52.7 \%$ are completed, but with an average cost overrun of $189 \%$, and many of these did not contain all the functionalities of original specifications; and 16.2\% are completed in-time and on-budget (Hays, 1997; Turban et al. 2001). Ambler (1999) determined that the estimated failure rate of large-scale software development since the early 1980s is $85 \%$. Jeong and Klein (1999) note that more complex systems are susceptible to high failure. According to Laudon and Laudon (1999), a complex package is one which contains more than 400 programs and 500,000 lines of codes. Harris (2000) stated that Microsoft Office suite contains 10 million lines of codes. Most of the integrated packages can be considered large and complex, and therefore have an inherent risk of failure. Turban et al. (2001) have stated that because of associated risks, some managers refuse to develop systems that require budgets over $\$ 1$ million, take more than one year, or require more than ten people for completing the project. Agrawal (2005a) stated that the higher costs and risks are associated in development of organization specific software and therefore, organizations are using off-the-shelf/ERP packages in higher proportion compared to proprietary packages. In the past, in-house development was popular due to the flexibility needed in the packages and the control on the development cycle. Because of the reusability of codes and customizability, the object oriented approach results in higher software development productivity. It will also lead to increased flexibility, increased predictability, and few errors (Nidumolu and Knotts, 1998). However, the faster rate of obsolescence, high cost, and risk factor will make the in-house development option unattractive.

The desired characteristics of the software solution include ease of use and reductions in risks and costs. According to O'Brien (1999) and Turban et al. (2001), the trend in software is towards off-the-shelf/ERP solutions, object-oriented programming, artificial intelligence, and natural language processing. The natural language processing will lead to simple user interface. In the case of the off-the-shelf/ERP solutions, it is possible to get reliable predictions of costs of acquisition, implementation, and use (Heikkila et al., 1991; Laudon and Laudon, 1999). Furthermore, these software packages are available without delay and can save up to $50 \%$ or more in development efforts. In addition, organizations can save high maintenance costs associated with in-house developed packages. The maintenance costs of in-house developed packages are as high as $80 \%$ of the corporate IT budget (Turban et al. 2001). Turban et al. (2001) also stated that with installation of some new software like ERP, organizations also have opportunities to upgrade their processes since the best practices are in-built in the packages. 
Figure 4 - IT Workforce Demand Framework

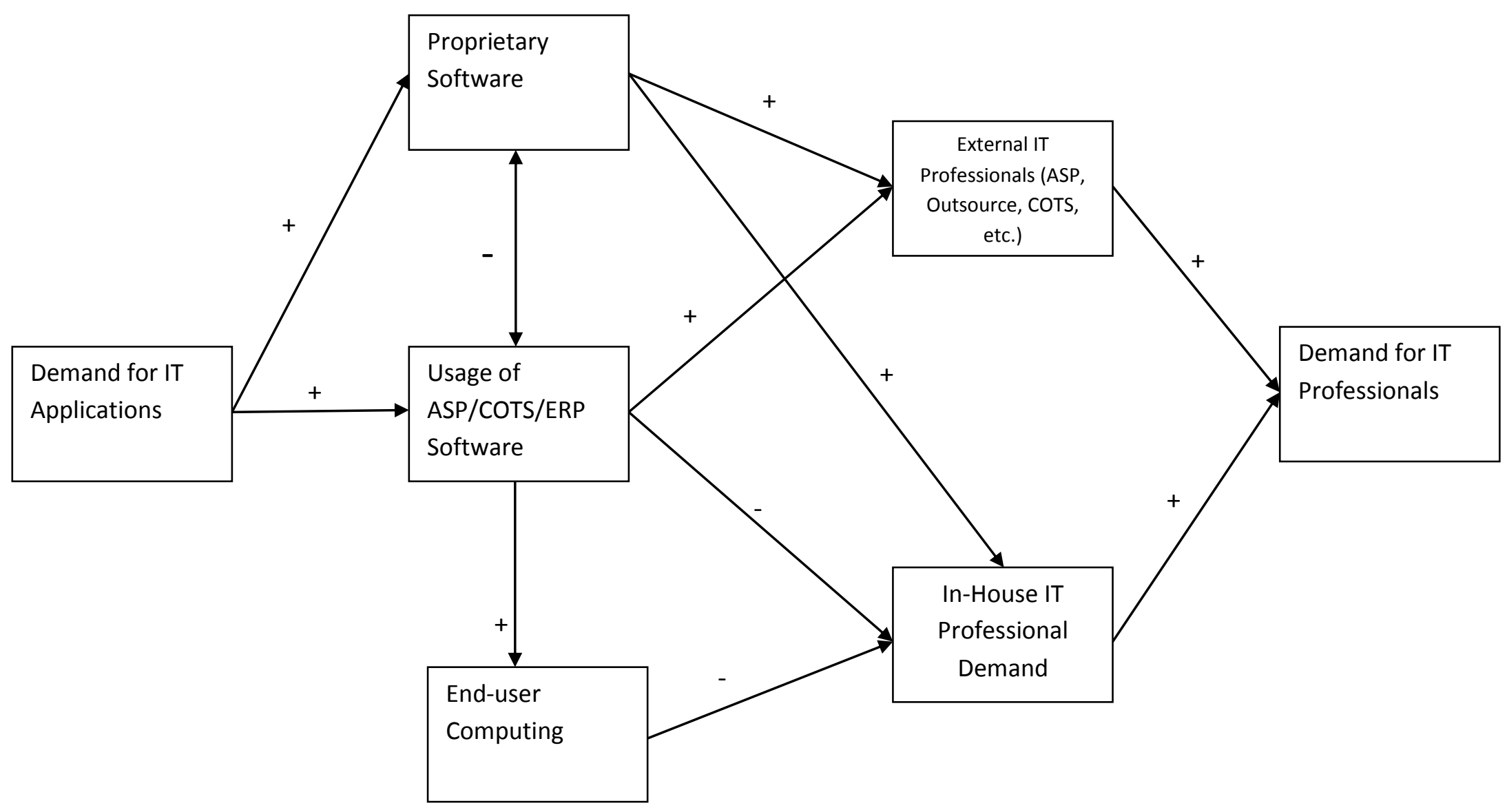


Agrawal, et al. (2001) argued that a move from proprietary to COTS packages will reduce cost at the expense of flexibility. If IT's role is only a strategic necessity and not a source of competitive advantage, then the substantial risks and high investments associated with proprietary packages are not desirable. In the turbulent environment with faster obsolescence in product/services, the combination of limited time available for development and the need for frequent changes will also make the option of proprietary packages infeasible and unattractive (Agrawal, 2005d) and the uses of commercial off-the-shelf/ERP packages will be in higher proportion compared to proprietary/customized packages (Agrawal 2005a). Thus, it does not seem possible in a short period for organizations to develop the complex and integrated large size packages which can be used for a short amount of time. Additionally, such projects may require a very large in-house IT department with continuous training and upgrades of technology. Under this situation the organizations will tend to rely more on commercial off-the-shelf packages/ERP solutions and outsourcing. Outsourcers, application service providers, and software houses using their economies of scale can meet their requirements economically. The current declining trends (compared to the projections of BLS) in the requirements of IT professionals, in addition to the earlier discussion, leads one to believe that the concentration of IT professionals will shift heavily from in-house IT departments to software houses, outsourcers, and application service providers. Moreover, it implies that the current declining trend in the requirement of IT professionals is the symptom of the higher use of readily available solutions, i.e. production and usage of more and more COTS/ERP solutions.

H4: As more companies adopt COTS software, the demand for IT professionals at COTS development firms will increase.

H5: As more companies adopt COTS software, the demand for in-house IT software development professionals will decrease.

H6: As more companies adopt COTS software, the availability of the COTS applications will lead to a growth in end-user computing.

The increase in usage of COTS software will lead to lesser demand for programmers and higher demand for system analysts including project managers. The decline in programmers' occupation will lead to offering fewer courses in programming languages for systems analysts/project managers.

\section{PROPRIETARY SOFTWARE}

The shifting role of IT as a strategic necessity will affect strategic decisions regarding the level of corporate investment in IT (Carr, 2003). When organizations have a possibility of strategic advantage, the organizations will maximize investments and develop proprietary application packages, maintaining the control on the software development and the flexibility in the packages.

Organizations such as Wal-Mart, Dell, and Jet-Blue have used Information Technology in order to gain a competitive advantage in the marketplace (Wailgum 2007). By using proprietary software many companies were able to add capabilities that were hard for their competitors to copy as long as they remained confidential. In a free market, it is very difficult to get sustainable competitive advantages (Porter, 1980). The time to duplicate is very short (months not years) once a rival's IT is understood. In recent years companies have begun to shift to COTS software for an increasing percentage of their applications. Even companies such as Wal-Mart that have traditionally believed that technology should be built to support best practice business procedures have started to adopt best of breed commercial application for business intelligence and other infrastructural technological needs (Wailgum, 2007) while at the same time building new custom applications when there is a potential to gain a large strategic advantage.

When firms decide to build their own proprietary software applications they can either build the applications in house or they can outsource the development of the application. If the application is built in-house the demand for in-house software developers will increase. If the application is built by a professional software development shop the demand for software developers will increase. In both scenarios there will be an increased demand for more programming courses in computer science/information systems curriculum design. 
H7: As more companies adopt proprietary software, the demand for in-house IT software development professionals will increase.

H8: As more companies adopt proprietary software, the demand for IT professionals at COTS development firms will increase.

\section{END-USER COMPUTING}

The increased demand for knowledge workers is partially fueled by the increased adoption of End-user computing (EUC). The growth in the importance of information technology as part of an enterprises basic infrastructure is augmented by evolutions in hardware, software, and the graphic user interface (GUI) which facilitates the use of IT applications by many end-users. Brancheau et al. (1996) concluded that the effectiveness of software development has been a key management information systems issue since the 1980s. This has caused a backlog of application software to be developed by IT professionals. The growth in end-user computing is one of the solutions to handle such a backlog of information demand. Trends in hardware and software such as miniaturization, speed, connectivity, interactivity, multimedia, and affordability (Sawyer and William, 2003) are also expected to contribute to the growth of End-users computing. According to O'Brien (1999) and Turban et al. (2001), the trends in software acquisition are towards object-oriented programming, artificial intelligence, natural language processing and commercial off-the-shelf/ERP solutions. The control of information systems departments on their manpower and IT budget has been decreasing and has shifted to end-users (Edberg and Bowman, 1996; He et al., 1998; Lucas, 2000).

The end-users are taking more and more responsibilities of information systems applications, and their involvement is also positively correlated with the success of information systems (Doll and Torkzaddah, 1988; McLean et al., 1993; Winter et al., 1997). Turban et al. (2001) claimed that many of the user requirements are smaller in size and can be developed by end-users themselves.

The modular approach in an object-oriented system makes some programming jobs much less complex, and allows end users to accomplish some functions that formerly required professional programmers. Furthermore, because of the reusability of codes and customizability, the object oriented approach results in higher software development productivity. Agrawal et al. (2001) claimed that the object-oriented approach would make the development process simple, enhancing customizability and contributing to the growth of EUC. These projections have been largely born out and are expected to continue.

Expert systems and other forms of artificial intelligence (AI) hastened the trend toward end-user computing. The use of AI helps businesses make decision better and faster. As these tools have spread throughout businesses their use has become common and continues to spread to jobs throughout the corporate hierarchy. Examples range from executives using applications that utilize artificial intelligence to build complex risk analysis models to cashiers us AI to identify produce (Sadahiro, Checkley, and Trivedi, 2001).

The natural language processing will lead to simple user interface. It will also lead to increased flexibility, increased predictability, and fewer errors (Nidumolu and Knotts, 1998). The graphical user-interface (GUI) makes software user friendly and allows end-users to communicate with the application more effectively in their familiar vocabulary.

Agrawal and Kotcherlakota (2006) asserted that in a stable IT environment end-users will make more use of the technical component of IT. Contrarily, in an unstable environment the end-users will not be able to work effectively with IT and will thus be required to look for tools and/or skills that are not IT based in order to meet their functional requirements. This reduction in the use of IT would also lead to a corresponding reduction in the need for end-user support but the enterprise would have a competitive disadvantage in regards to their technological infrastructure.

The trend toward more end-user computing will reduce the number of tasks that are required of in-house IT professionals as end users are increasingly able to accomplish tasks that formerly required an IT professional. This trend will be across industries. Some companies will see a growth in the number of IT professionals required to 
support functions not previously offered but the overall trend should be toward a reduction of in-house personnel dedicated to IT infrastructure demand.

H9: As more companies adopt end-user computing, the demand for in-house IT professionals will decrease.

The growth in End-users Computing will lead to offering few programming, database, and business intelligence courses in the core curriculum for all graduates.

\section{IN-HOUSE IT PROFESSIONAL DEMAND}

The shift to more end-users control has led to information systems departments to reduce control of their manpower and IT budget (Edberg and Bowman, 1996; He et al., 1998; Lucas, 2000). The main reason for this shift is credited to the availability of user-friendly software, knowledgeable end-users and extensive company support to EUC (Turban et al., 2001). The end-users are taking more and more responsibilities of information systems applications, and their involvement is also positively correlated with the success of information systems (Doll and Torkzaddah, 1988; McLean et al., 1993; Winter et al., 1997). Agrawal (2005b) stated that the growth in EUC will increase the requirements of help desk support. Furthermore, the faster obsolescence in products/services and turbulent environment will lead to higher involvement of End-users in implementation and maintenance of software packages (Agrawal, 2005c). As end-users start to become more involved in areas that were once exclusively within the purview of IT departments, a decline in the requirements of in-house software developers is likely to occur (Agrawal, 2005b). The net overall effect will be a reduction in the number of in-house IT professionals required. Furthermore, the usage of COTS/ERP packages in higher proportion will further lead to a decline in the requirements of in-house IT professionals. Lazowska (2008) asserted that $70 \%$ of all IT jobs are with "IT consumers" (company that use it) rather than with "IT producers" (companies that invent it). The increased usage in COTS/ERP packages will lead to a growth in $30 \%$ segment and shrinkages in $70 \%$ segment.

H10: There is a positive correlation between the demand for In-house IT professionals and the total demand for all IT professionals.

\section{PROJECTED DEMAND FOR EXTERNAL IT PROFESSIONALS}

We predict that the demand for external IT professionals will increase. This will be driven by a shift toward more commercial off-the-shelf software applications, increased utilization of application service providers (ASPs), as well as mainstream outsourcing arrangements. Commercial off-the-shelf solutions include ERP applications and other packages that allow for customization. The advantages that specialized developers have in areas such as scale, experience, and specialization are difficult for an in-house team to compete against on a consistent basis (Klepper and Jones, 1998). Companies that develop software as their primary business also have the added advantage of being able to more easily introduce the latest technologies and skills into their labor force without a disruption of their business.

H11: There is a positive correlation between the demand for External IT professionals and the total demand for all IT professionals.

\section{CONCLUSION}

IT curriculum committees are faced with an ever more difficult challenge as they try to retain a curriculum core of knowledge that should be universally understood by all graduates in their departmental areas. At the same time, these committees are trying to predict what knowledge is most needed by the rapidly changing society so that students can have both the depth and breadth of knowledge they will need upon graduation. In order to facilitate the planning process we have developed a conceptual framework that is based upon a review of megatrends within the IT area that will drive the market.

The framework was developed by looking at macro level trends. One trend found is that some industry experts are strongly predicting the demise of corporate IT departments (Keefe, 2002), allowing business users the 
capability to take on operational-level technical tasks, freeing a small core of IT staffers to focus on analytical and strategic issues (Agrawal et. al., 2001, Agrawal, 2005a-2005b, Keefe, 2002). Agrawal (2001 et. al., 2005a-2005b) and Keefe (2002) further argued that because technology is becoming easier for end users, and considering IT function as problematic to manage, a lot of IT processes will move to outsourcers. The cost and risk of developing applications in-house will also prompt some organizations to rely more on customized or off-the-shelf packages, including ERP software. However, each college has its own unique group of stakeholders to be served so each school will need to review the model looking at the environment for their school and determine the effects of the short and long term trends upon their program viability. The framework presented in the paper is general and can be used as a guide by curriculum review committees during the department's annual assessment.

\section{AUTHOR INFORMATION}

Vipin K. Agrawal, after receiving his undergraduate degree (in Electronics and Communications Engg.), went to Texas A\&M University for his M.S. (Finance) and the University of Texas at Austin for his PhD (Finance). Since 2003, he has been an Assistant Professor at California State University at Fullerton. In addition, he was Visiting Assistant Professor at the University of Texas at Austin for the 2006-2007 academic year. His research has been published in journals such as The Quarterly Review of Economics and Finance and has been presented at various conferences such as the Financial Management Association and National Decision Sciences Institute.

Vijay K. Agrawal is an Associate Professor of Management Information Systems in the College of Business and Technology at the University of Nebraska at Kearney. His areas of interest are management information systems, operations management, and accounting. He received his B.S. in mechanical engineering from the University of Indore, MBA from the University of Toledo, and M.S. in computer science from Bowling Green State University. He received his Ph.D. from Jamia Millia Islamia (University of Millia Islamia), New Delhi, India. He has published in Production and Operations Management, National Social Science Journal, Global Journal of Flexible Systems Management, Encyclopedia of Operations Research and Management Science, and others.

Frank Tenkorang had his B.S. degree from University of Ghana. He obtained his M.S. and Ph.D. degrees from University of Wyoming and Purdue University, respectively in 2002 and 2006. Frank is currently an assistant professor at University of Nebraska, Kearney. He does research in agricultural economics. His last publication on long-term fertilizer demand was published in Nutrient Cycling in Agroecosystems.

A. Ross Taylor is an Assistant Professor of Management Information Systems in the College of Business and Technology at the University of Nebraska at Kearney. His areas of interest are computer-aided decision making, rural economic development, and social media. He received his Ph.D. from the University of Arkansas. His research has been published in journals such as European Journal of Operations Research and Journal of Behavioral Studies in Business.

\section{REFERENCES}

1. $\quad$ AACSB (2002). Business schools at risk. BizEd, May/June, pp. 48-54.

2. Agrawal, V.K. and Kotcherlakota, V. (2006). Impact of Environmental Pressures and Culture on Factors Influencing the Requirements of Human Resources Engaged in IT Applications. Indian Journal of Business and Economics (IJEB), Vol. 5, No. 1, June, pp 15-40.

3. Agrawal, V.K. (2005a). From Proprietary Software to Off-the-shelf/ERP Solutions: Identifications of Critical Factors. National Social Science Journal, 23(2), 9-32.

4. Agrawal, V. K. (2005b). Critical Factors Influencing the Requirements of Human Resources Engaged in IT Applications. National Social Science Journal, 24(1), 1-32.

5. Agrawal, V.K. (2005c). Implications of Environmental and Cultural Factors on the Growth in End-users Computing. National Social Science Journal, 24(2), 1-14.

6. Agrawal, V.K. (2005d). "Implications of Environmental and Cultural Factors on the Trends in Usage of Various Categories of Software. National Social Science Journal**, Volume 25 No. 1, pp 1-15.

7. Agrawal, V.K., Haleem, A. and Sushil. (2001). Trends in the Demand for Different Categories of Software and Human Resources, Proceedings of the Annual Conference of Midwest Decision Sciences Institute, 4. 
8. $\quad$ Ambler, S. (1999) Comprehensive Approach Cuts Project Failure, Computing Canada, 25 (1), pp.15-16.

9. Applegate, L. M, Austin, R. D., and McFarlan, F. W. (2007). Corporate Information Strategy and Management: Text and Cases. New York: NY, McGraw Hill/Irwin

10. Bennis, W.G. and O’Toole, J. How business schools lost their way. Harvard Business Review, May 2005 , 83(5).

11. Brancheau J.C., Janz, B.D. and Wetherbe J.C. (1996). Key issues in information systems management: 1994-95, SIM delphi results. MIS Quarterly, 20, 2, June, 225-242.

12. Broadbent, M. and Weil, P. (1997). Management by maxim: How business and IT managers can create IT infrastructures. Sloan Management Review, 38, 3, Spring, pp 77-92.

13. Carr, N.G. (May 2003). IT Doesn't Matter. Harvard Business Review. Boston: Harvard

14. Business School Press.

15. Dohm, A. and Shniper, L. (2007). Occupational Employment Projections to 2016, Monthly Labor Review, Bureau of Labor Statistics. Last Accessed February 12, 2009

http://www.bls.gov/opub/mlr/2007/11/art5full.pdf.

16. Doll, W. J., and Torkzaddeh, G. (1988). The measurement of end-user computing satisfaction. MIS Quarterly, June, 259-274.

17. Edberg, D. T., and Bowman B. J. (1996). User-developed applications: An empirical study of application quality and developer productivity. Journal of Management Information Systems, 13, 1, Summer, pp.167.

18. El Sawy, O. A., Malhotra, A., Gosain, S., and Young, K. M. "IT-Intensive Value Innovation in the Electronic Economy: Insights from Marshall Industries," MIS Quarterly (23:3), 1999, pp. 309-335.

19. Fleming, D.L. (2008), Building Bridges to connect the disconnects: An analysis of business program design processes. 1(2) 21-46.

20. Forrester Research Incorporated. (2009). US IT Market Outlook: Q1 2009 Our Bleak Alternative View Moves Closer To Reality. Cambridge, MA: Bartels, A..

21. Gartner. (2009). Gartner Says Worldwide IT Spending to Decline 3.8 Per Cent in 2009. Stamford, Conn.

22. Gerdes, L. (2005). "B-School With a Niche," Business Week, Sept. 5, 2005, 70-72.

23. Gilder, G. (2002), Telecosm: The World After Bandwidth Abundance. Touchstone.

24. Harris, Roger W. (2000). School of thought in research into end-user computing success. Journal of EndUser Computing, Vol.12, No.1, January - March , pp.24-34.

25. Hayes, F. (1997) Managing User Expectation, Computerworld, 31(4), pp.8-9.

26. He, Z. M., Kusy K. M., and Zhao T. (1998). A survey study of the current IS usage in the Chinese manufacturing industry. Information and Management, 34, 285-294.

27. Hecker, D. (November 2006). Occupational employment projections to 2014, Monthly Labor Review, pp. 70-101 Last Retrieved February 10, 2009 http://www.bls.gov/opub/mlr/2005/11/art5full.pdf.

28. Hecker, D. (February 2004). Occupational employment projections to 2012, Monthly Labor Review, pp. 80-105. Last Retrieved February 10, 2009 http://www.bls.gov/opub/mlr/2004/02/art5full.pdf

29. Hecker, D. (November 2001). Occupational employment projections to 2010, Monthly Labor Review, pp. 57-84, Last Retrieved February 10, 2009 http://www.bls.gov/opub/mlr/2001/11/art4full.pdf.

30. Heikkilä, J., T. Saarinen, T. and Sääksjärvi, M. (1991). Success of software packages in small businesses: An exploratory study. European Journal of Information Systems, Vol.1, No.3, pp.159-169.

31. Hof, R. (August 17, 2003). Andy Grove: We can't even glimpse the potential. Business Week Online. http://www.businessweek.com/@ @GovuBoUQaQmEPwkA/magazine/content/03_34/b3846612.htm

32. Jeong, J. J. And Gary Klein. (1999) Risks To Different Aspects Of System Success, Information And Management, 36, 263-272.

33. Keefe, P. (2002, Sep 16). Mapping IT's Future. Computerworld.

34. Klepper, R. and Jones, W.O. (1998). Outsourcing Information Technology, Systems, \& Services. Upper Saddle River, NJ: Prentice Hall.

35. Lazowska, E. (2008). Computer Science Enrollment: The Real News. Computer Community Consortium, July 11, http://www.cccblog.org/2008/07/11/computer-science-enrollment-the-real-news/

36. Laudon, K.C., and Laudon, J.P. (1999). Essentials of Management Information Systems: Transforming Business and Management. Upper Saddle River, NJ: Prentice Hall, 1999.

37. Li, M.F., and Ye, R.L. (1999). Information Technology and Firm Performance: Linking with Environmental Strategic Managerial Contexts. Information and Management, 35, 53-51. 
38. Lucas, H. C. (2000). Information Technology for Management, Seventh Edition. New York: McGraw-Hill, Inc.

39. Mahmood, M.A., and Mann, G. (1993). Measuring the organizational impact of information technology investment: An exploratory study. Journal of Management Information Systems, 10, 1, 97-122.

40. Matheson, L. and Tarjan, R. (1998) 'Culturally induced information impactedness: a prescription for failure in software ventures', Journal of Management Information Systems, Vol. 15, No. 2.

41. McKenna, J.F., Cotton, C.C. and Van Auken, S. (1995). Business School Emphasis on Teaching, Research, and Service to Industry: Does Where You Sit Determine Where You Stand? Journal of Organizational Change Management, Vol. 8, 2, 3- 16.

42. McLean, E.R., Kappelman L.A., and Thompson J.P. (1993). Converging end-user computing and corporate computing. Communications of the ACM, 36, 12, 79-92.

43. McNamara, D. E. (2006). The Relevance Of Business School Education, What Do You Think? Journal of College Teaching \& Learning, 3, 11, 1-14.

44. Metcalfe, R. (June 2004). Why IT matters. Technology Review. Retrieved January 5, 2009. http://www.technologyreview.com/articles/04/06/metcalfe0604.asp?p=1

45. Mintzberg, H. (2004). Managers Not MBAs: A Hard Look at the Soft Practice of Managing and Management Development. Berrett-Koehler, San Francisco, CA.

46. Nidumolu, S. R., and Knotts, G.W. (1998). The effect of customizability and reusability on perceived process and competitive performance of software firms. MIS Quarterly, June, 105-137.

47. O’Brien, J. A. (1999). Management Information Systems: Managing Information Technology in the Internetworked Enterprise, 4th Edition. New York: Irwin-McGraw Hill.

48. $\quad$ Porter, M. (1980). Competitive Strategy. New York: Free Press.

49. Porter, M. E. (2001) Strategy and the Internet. Harvard Business Review.

50. Sadahiro, I, Checkley, D. Trivedi, M., (August 2001). "REFLICS: Real-time flow imaging and classification system", Machine Vision and Applications, Volume 13, Number 1/August, 2001.

51. Williams, B. \& Sawyer, S. (2003). Using Information Technology: A Practical Introduction to Computers and Communications, 5/e. New York: McGraw-Hill.

52. Scott Morton, M.S. (1991) The Corporation of the 1990s: Information Technology and Organizational Transformation, Oxford University Press

53. Tapscott, D. (2001), "Rethinking strategy in a networked world (or why Michael Porter is wrong about the internet)", Strategy \& Competition, No.3rd quarter.

54. Turban, E., E. McLean, and Whetherbe, J. (2001). Information Technology for Management: Making Connections for Strategic Advantages, 2nd updated edition. New York, NY: John Wiley and Sons, Inc.

55. Wailgum, T. (October 2007). How Wal-Mart Lost Its Technology Edge, CIO, Retrieved February 10, 2009 from http://www.cio.com/article/print/143451.

56. Winter, S. J., Chudoba K. M., and Gutek B. A. (1997). Misplaced resources? Factors associated with computer literacy among end-users. Information and Management, 32, 29-42. 